\title{
Kepemimpinan Kepala Sekolah Dalam Meningkatkan Tenaga Kependidikan Berbasis Kearifan Lokal Di SMAN 3 Wera
}

\section{${ }^{1}$ Syaifullah, ${ }^{2}$ Nurnazmi dan ${ }^{3}$ Nikman Azmin}

\author{
Program Studi Pendidikan Sosiologi STKIP Bima \\ Jalan Piere Tendean Kel. Mande Tlp.Fax (0374) 42801, Bima 84191, Indonesia \\ Author Correspondent; syaifullahsosiologi@gmail.com
}

\begin{abstract}
Abstrak
Kepemimpinan kepala sekolah salah satu kunci keberhasilan proses pendidikan di sekolah. Kepala sekolah sebagai pemimpin pendidikan berperan dan bertanggungjawab atas tercapainya tujuan pendidikan melalui upaya pemberdayaan pendidik dan tenaga kependidikan. Kepala sekolah sebagai pucuk pimpinan pendidikan dalam mengelola bawahannya tidak serta merta dalam menjalankan organisasi, tetapi ada seni atau ilmu yang mengatur tentang pengelolaan manusia yang ada dalam organisasi pendidikan tersebut. Namun permasalahannya adalah kepala sekolah belum sepenuhnya melakukan berbagai tindakan inovatif dalam meningkatkan kreativitas pendidik dan tenaga kependidikan seperti memotivasi dan menyemangati pendidik dan tenaga kependidikan di SMAN 3 Wera Kabupaten Bima. Jenis penelitian yang digunakan adalah deskriptif kualitatif yang berusaha menganalisis dan mendeskripsikan kepemimpinan kepala sekolah dalam melakukan pengembangan pendidik dan tenaga kependidikan di SMAN 3 Wera Kabupaten Bima. Teknik pengumpulan data dalam penelitian ini menggunakan, observasi, wawancara, dan studi dokumenter. Kemudian pengecekan keabsahan data dilakukan dengan cara triangulasi dan teknik analisis data dilakukan melalui reduksi data, penyajian data dan verikasi/kesimpulan.
\end{abstract}

Kata Kunci : Kepemimpinan, Tenaga Kependidikan, SMAN 3 Wera. 


\section{PENDAHULUAN}

Kepemimpinan merupakan salah satu faktor penting yang mempengaruhi berhasil tidaknya lembaga pendidikan. Kepala sekolah sebagai pemimpin lembaga pendidikan formal yang memiliki tugas dan tanggungjawab yang sangat besar (Handriyani et al, 2018). Kepala sekolah merupakan motor penggerak yang akan menentukan bagaimana tujuan sekolah dan pendidikan pada lembaga tersebut dapat di wujudkan. Sebagai pemimpin lembaga formal, dalam hal ini kepala sekolah bertanggungjawab atas tercapainya tujuan pendidikan melalui upaya pemberdayaan pendidik dan tenaga kependidikan di sekolah (Subiyanto, 2018). Untuk mewujudkan hal tersebut, seorang kepala sekolah sebagaimana yang di sampaikan oleh Bush (Hidayat dan Marfuah, 2018) harus memiliki sikap yang responsif terhadap kebutuhan, menghargai keahlian dan keterampilan dari para guru, selalu berusaha untuk mengoptimalkan pemanfaatan keahlian koleganya, seorang kepala sekolah harus lebih menonjolkan keahlian dari pada otoritas kemajuan, yakni pengambilan putusan tentang sesuatu harus di pertimbangkan berdasarkan pandangan dan pendapat mereka yang memiliki pengetahuan dan keahlian tentang hal tersebut dari pada menggunakan otoritas kepemimpinannya.

Hasil studi peneliti pada 01/02/2019, SMAN 3 Wera Kabupaten Bima merupakan satu dari sekian sekolah yang menjalankan program pengembangan pendidik dan tenaga kependidikan seperti adanya workshop kearifan lokal, pelatihan-pelatihan, pembinaan, dan lain sebagainya, semua itu dilakukan dalam rangka meningkatkan kualitas pendidik dan tenaga kependidikan di sekolah untuk mencapai Peraturan Pemerintah Nomor 19 Tahun 2005. Namun permasalahannya adalah kepala sekolah belum sepenuhnya melakukan berbagai tindakan inovatif dalam rangka meningkatkan kreativitas pendidik dan tenaga kependidikan di SMAN 3 Wera Kabupaten Bima. Hal disebabkan oleh kepemimpinan kepala sekolah yang masih kurang responsif terhadap peningkatan kualitas pendidik dan tenaga kependidikan, karena pertumbuhan sistem pendidikan tanpa memfungsikan pengelolaan atau manajemen pendidikan tidak mungkin dapat membina pertumbuhan sekolah, prosedur pengelolaan harus di terapkan dengan sistematis (Sobri, 2018).

Pengembangan profesional pendidik dan tenaga kependidikan dirasa semakin penting karena tuntutan pekerjaan atau 
jabatan. Pengembangan tenaga pendidikan dalam hal ini adalah usaha-usaha untuk meningkatkan mutu pendidikan serta efisiensi kerja seluruh tenaga sekolah yang ada (Anna, 2018). Dalam hal ini, kepala sekolah sebagai pimpinan lembaga pendidikan dituntut harus memiliki grand design dalam mengelola tenaga sekolah karena pada prinsipnya kepala sekolah harus mampu memelihara tenaga kependidikan agar tetap profesional.

\section{METODE PENELITIAN}

\section{Jenis Penelitian}

Jenis penelitian yang digunakan adalah deskriptif kualitatif yang berusaha menganalisis dan mendeskripsikan aktivitas kepemimpinan kepala sekolah SMAN 3 Wera Kabupaten Bima

\section{Waktu dan Tempat Penelitian}

Penelitian ini selama 3 bulan dilaksanakan di SMAN 3 Wera Kabupaten Bima dengan alasan sekolah tersebut merupakan sekolah yang melaksanakan program pendidikan atau pelatihan dalam hal ini workshop supervisi pendidik dan tenaga kependidikan dengan tujuan untuk meningkatkan kinerja pendidik dan tenaga kependidikan

\section{Prosedur Penelitian}

Adapun prosedur dalam penelitian ini yaitu menggunakan Observasi atau pengamatan (observasi), Wawancara dan

Studi dokumenter.

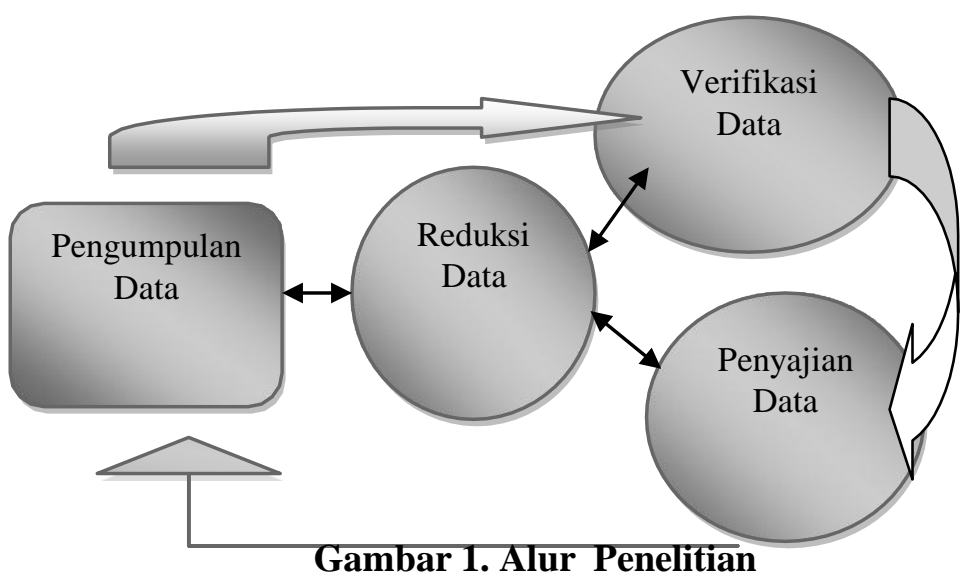

1. Observasi

Observasi atau pengamatan ini peneliti terlibat dalam kegiatan seseorang atau kelompok yang sedang diamati di SMAN 3 Wera. Observasi yang dilakukan seperti menggali informasi mengenai adanya program workshop supervisi pendidikan. Observasi ini ditujukan kepada kepala sekolah selaku pemimpin lembaga pendidikan dengan menggunakan pendekatan persuasif agar apa yang menjadi tujuan observasi tercapai dan berjalan dengan baik. Dengan observasi, maka data yang di peroleh akan lengkap, tajam, seperti data mengenai guru yang mengikuti pelatihan kurikulum, guru yang mengikuti diklat pada dinas pendidikan provinsi, guru yang 
mengikuti bimtek pada dinas pendidikan luar kota, dan sampai mengetahui bagaimana keadaan sebenarnya di lapangan seperti mengenai kepemimpinan kepala sekolah dalam melakukan pengembangan terhadap pendidik dan tenaga kependidikan dan seterusnya.

\section{Wawancara}

Wawancara adalah salah satu langkah untuk mengumpulkan data dengan mengajukan pertanyaan baik secara lisan maupun secara tertulis. Dengan wawancara dapat mengetahui bagaimana peran kepemimpinan kepala sekolah, sampai kemudian upaya yang dilakukan kepala sekolah dalam pengembangan pendidik dan tenaga kependidikan di SMAN 3 Wera Kabupaten Bima.

\section{Studi Dokumenter}

Studi dokumenter adalah cara mengumpulkan data dengan mencatat data-data yang berkaitan dengan program pendidikan atau pelatihan mengenai pengembangan pendidik dan tenaga kependidikan di SMAN 3 Wera Kabupaten Bima dalam hal ini workshop supervisi pendidik dan tenaga kependidikan

\section{HASIL PENELITIAN}

\section{Kepemimpinan Kepala Sekolah di Tenaga pendidik dan Kependidikan SMAN 3 Wera Kabupaten Bima}

Kepala sekolah merupakan pimpinan tertinggi di semua sekolah. Pola kepemimpinannya akan sangat berpengaruh bahkan sangat menentukan terhadap kemajuan sekolah tersebut. Keberhasilan suatu lembaga pendidikan sangat tergantung pada kepemimpinan kepala sekolah. Karena dia sebagai pemimpin di lembaganya, maka dia harus mampu membawa lembaganya ke arah tercapainya tujuan yang telah ditetapkan, dia harus mampu melihat adanya perubahan dan mampu melihat masa depan dalam kehidupan globalisasi yang lebih baik. Seorang kepala sekolah perlu menerapkan gaya kepemimpinannya untuk mengembangkan profesionalisme guru-guru dan staff dibawahnya dan membangun semangat motivasi yang tinggi. Hasil temuan mengenai kepemimpinan kepala sekolah di SMAN 3 Wera adalah menerapkan gaya kepemimpinan demokratis. Kepemimpinan demokratis lebih kepada kepala sekolah selaku pemimpin mau memberikan ide atau gagasan, menerima dan bahkan mengharapkan pendapat dan saran-saran 
dari guru-guru dan staff di SMAN 3 Wera Kecamatan Wera Kabupaten Bima, juga kritik-kritik yang membangun. Kepala sekolah SMAN 3 Wera Kecamatan Wera adalah pemimpin yang aktif, dinamis, terarah yang berusaha memanfaatkan setiap personil untuk kemajuan dan perkembangan organisasi pendidikannya. Kepemimpinan yang mengedepankan musyawarah untuk pengambilan keputusannya. Suatu Kepemimpinan sesungguhnya bisa berlangsung dimana saja, karena kepemimpinan merupakan suatu proses yang berupaya mempengaruhi orang untuk melakukan sesuatu dalam usaha mencapai maksud tertentu. Didasarkan dari definisi kepemimpinan yang berbeda-beda mengandung persamaan arti yang bersifat umum. Seorang pemimpin adalah orang yang memberikan inspirasi, membujuk, mempengaruhi dan memotivasi orang lain.Menurut (Mulyasa, 2012), salah satu unsur komponen pendidikan yang sangat berperan dalam meningkatkan kualitas pendidikan adalah kepala sekolah. Bentuk tanggungjawab pada penyelenggaraan kegiatan pembelajaran, pembinaan tenaga kependidikan, administrasi dan pemeliharaan sarana dan prasarana dipegang oleh kepala sekolah.

\section{Profesionalisme Kerja Tenaga Pendidik dan Kependidikan di SMAN 3 Wera Kecamatan Wera Kabupaten Bima.}

Pengembangan profesi adalah kegiatan atau aktivitas guru dalam rangka menerapkan ilmu dan pengetahuan, teknologi dan ketrampilan untuk meningkatkan mutu, baik bagi proses belajar mengajar dan profesional tenaga kependidikan lainnya. Kemampuan professional seorang guru dapat dikembangkan dengan cara dilakukan penataran, baik dalam rangka penyegaran maupun peningkatan kemampuan, misalnya on the job training, workshop, seminar, diskusi panel, rapat-rapat, simposium, konferensi, dan sebagainya (Saud, 2009). Menurut Rohiat (2008) mengatakan bahwa Pengembangan Profesionalisme guru meliputi

Peningkatan kompetensi guru bidang pengembangan kurikulum, b) Peningkatan kompetensi guru bidang manjemen pembelajaran, c) Peningkatan kompetensi guru bidang pengembangan strategi pembelajaran (CTL), d) Peningkatan kompetensi guru bidang pengembangan media pembelajaran. e. Peningkatan kompetensi guru dalam penggunaan ICT (komputer, internet, dan perangkat ICT 
lainnya, f) Peningkatan kompetensi dalam PTK dan Peningkatan kompetensi dalam bidang bahasa inggris (Yuliani, 2015).

Kepala sekolah SMAN 3 Wera Kecamatan dalam mengembangkan profesionalisme guru dengan mengikutsertakan guru dan karyawan dalam pengembangan uji kompetensi dalam hal ini adalah berbagai pelatihan atau diklatdiklat, memberikan dorongan semangat dan motivasi kepada guru dan karyawan untuk studi lanjut atau tugas belajar ke jenjang pendidikan yang lebih tinggi, mengikutkan MGMP (kegiatan profesional guru), meningkatkan dan menambah fasilitas sarana dan prasarana penunjang, memberikan tunjangan kesejahteraan guru serta membentuk forum silaturrahmi seluruh warga sekolah untuk meningkatkan interaksi sosial dan komunikasi yang baik. Hasil penelitian ini sesuai dengan penelitian Rika (2017) yang menyimpulkan bahwa dalam mengembangkan profesionalisme guru, kepala sekolah dapat melakukan beberapa kegiatan, diantaranya: 1) memberikan kesempatan kepada guru untuk mengikuti diklat atau pelatihan-pelatihan, 2) mengikutkan guru dalam program sertifikasi, 3) memberikan kesempatan kepada guru untuk melanjutkan studinya, 4) melaksanakan kerjasama dengan lembaga atau instansi lain, dan 5) melaksanakan kunjungan ke sekolah lain. Jadi dapat disimpulkan bahwa pengembangan profesionalisme guru pada dasarnya adalah peningkatan kualitas kompetensi guru. Pengembangan profesi guru merupakan strategi dari kepala sekolah untuk dapat membantu guru agar lebih efektif dalam melaksanakan tugasnya dan bertujuan untuk mewujudkan guru yang profesional sesuai harapan sekolah dengan ikut serta dalam pelatihan peningkatan uji kompetensi melalui diklatdiklat (Uray, 2018).

\section{Strategi Kepemimpinan Kepala Sekolah dalam Pengembangan Profesionalisme Tenaga Pendidik dan Kependidikan}

$$
\text { Strategi Kepemimpinan Pendidikan }
$$
adalah proses atau gaya untuk mempengaruhi orang lain atau sekelompok orang untuk mengerahkan segala usaha bersama guna pencapaian tujuan pendidikan melalui sasaran atau tujuan yang telah ditetapkan (Yusup, 2014) Strategi kepemimpinan kepala sekolah merupakan cara untuk mengatasi segala kendala atau tantangan dengan memanfaatkan segala sumber daya sekolah, termasuk meningkatkan profesioanlisme guru untuk mencapai 
tujuan sekolah. Strategi kepemimpinan kepala sekolah SMAN 3 Wera Kecamatan Wera Kabupaten Bima dalam mengembangkan profesionalisme guru, yaitu menerapkan gaya kepemimpinan demokratis yang memperhatikan hubungan antara pribadi dengan situasi sehingga dapat dijadikan sebagai sarana meningkatkan profesionalisme guru, artinya memandang bahwa guru sebagai partner dan memanusiakan manusia, memperhatikan perilaku-perilaku di lingkungan sekolah terhadap pribadinya dan situasi atau keadaan guru, staff dan peserta didiknya. Kepala sekolah juga memberikan hak-hak sepenuhnya kepada guru-guru, mengadak an pembin aan profesionalisme guru dengan mengirim guru-guru ikut dalam pelatihan diklat-diklat untuk meningkatkan uji kompetensi guru, mengadakan MGMP, mengirim guru-guru yang ingin melanjutkan pendidikan, melengkapi sarana dan prasarana yang diperlukan guru. Hal ini sebagaimana Zainuddin (2017) yang menyimpulkan bahwa kepala sekolah menerapkan kepemimpinan demokratis yang sudah berjalan cukup baik dan startegi kepemimpinan yang dilakukan untuk meningkatkan kinerja guru adalah dengan mengirimkan guru ke pelatihan diklat, mengadakan MGMP, mengadakan PKB dan menyusun RKAL. Hal ini mengindikasikan bahwa strategi kepemimpinan kepala sekolah dalam pengembangan profesionalisme guru dengan menerapkan kepemimpinan demokratis dapat memberikan kebebasan kepada guru dan karyawan untuk meningkatkan kompentensinya melalui pelatihan atau diklat agar kualitas dari guru berdampak positif bagi kemajuan kualitas pendidikan di sekolah (Rika, 2017).

\section{KESIMPULAN}

Kepemimpinan kepala sekolah SMAN 3 Wera Kecamatan Wera Kabupaten Bima menggunakan gaya kepemimpinan demokratis. Kepemimpinan demokratis artinya beliau selalu mengajak untuk bahu membahu bersama-sama dan selalu berusaha untuk memastikan bahwa semuanya mendapatkan informasi memadai dan berpartisipasi dalam mencapai tujuan sekolah serta selalu mengambil keputusan atas dasar kesepakatan bersama. Seluruh jajaran di sekolah adalah partner, semua saling mengisi, saling memperkuat sistem dalam rangka menuju satu tujuan yang sama yang akan dicapai. Kepala sekolah SMAN 3 Wera Kecamatan Wera Kabupaten 
Bima memimpin segala urusan di sekolah dengan memberikan kepercayaan dan melimpahkan sebagian tugasn dan wewenangnya kepada wakil kepala sekolah, guru dan staff. Pengembangan profesionalisme guru yang dilakukan kepala sekolah sebagai upaya peningkatan kompetensi profesionalisme guru, yaitu mengikutsertakan guru dalam pelatihan atau diklat untuk meningkatkan uji kompetensi guru, mendorong semangat dan motivasi guru untuk studi lanjut atau tugas belajar ke jenjang pendidikan yang lebih tinggi, organisasi profesi guru seperti MGMP, meningkatkan pelayanan dan penambahan fasilitas penunjang, memberikan tunjangan kesejahteraan guru serta membentuk forum silaturrahmi seluruh warga sekolah.

\section{DAFTAR PUSTAKA}

Anna, M.. 2018. Kepemimpinan Perubahan Kepala Sekolah Dalam Peningkatan Mutu Pendidikan. Jurnal Adminitrasi dan Manajemen Pendidikan, Volume 1 Nomor 3, Hal : 358-363

Azmin, N., \& Rahmawati, A. (2019). Skrining Dan Analisis Fitokimia Tumbuhan Obat Tradisional Masyarakat Kabupaten Bima. Jurnal Bioteknologi \& Biosains Indonesia (JBBI), 6(2), 259-268

Hidayat G,M. dan Marfuah A,S. 2018. Kepemimpinan Kepala Sekolah Dan Pengaruhnya Terhadap Peningkatan Pedagogik Guru Pendidikan Agama Islam Di SMP NEGERI 3 Karawang Jawa Barat. Jurnal Islamic Managemen, Volume 1, Nomor 2, Halaman: 207-232

Handriyani, T., Udin Syaefudin Saud dan

Dadang Suhardan. 2018. Mutu

Sekolah Antara Kepemimpinan

Kepala Sekolah Dan Kinerja Guru. Jurnal Administrasi Pendidikan Vol.XXV No.1, Halaman: 21-29

Mulyasa. 2012. Manajemen dan Kepemimpinan Kepala Sekolah. Jakarta: Bumi Aksara

Rika, A. 2017. Kepemimpinan Kepala Sekolah Dalam Pengembangan Profesionalisme Guru. Journal Fiaiunisi Vol.5, No.1, hal 108-128

Sobri, A. Y. 2018. Kepemimpinan Kepala Sekolah dalam Meningkatkan Kualitas Sekolah dalam Era Masyarakat Ekonomi ASEAN. Jurnal Manajemen 
Subiyanto, E. 2018. Subiyanto Evaluasi Peran Kepemimpinan Kepala Sekolah Terhadap Kinerja Guru Sd Negeri Mangli Kecamatan Kaliangkrik Kabupaten Magelang Tahun 2018. Jurnal Mitra Pendidikan, Volume 5, Nomor 3, Halaman: 264-273

Uray, I. 2018. Kepemimpinan Kepala Sekolah dalam Meningkatkan Guru. Jurnal Visi Ilmu Pendidikan Volume 2, Nomor 2 Halaman: 21-32

Yuliani, T. 2015. Faktor-Faktor Yang Mempengaruhi Kinerja Guru SMA
Negeri Di Balikpapan. Jurnal Akuntansi, Volume 1, Nomor 2 Halaman: 270-280.

Yusup, M. 2014. Peran Kepala Sekolah Sebagai Pemimpin Pemelajaran. Jurnal Administrasi Pendidikan. Volume 2, Nomor 2 Halaman: 21-32 Zainuddin, 2017. Strategi Kepala Sekolah Dalam Meningkatkan Kinerja Guru di Madrasah Aliyah Negeri Kabanjahe. Jurnal.UINSU, Vol. 1. No.2. hal

82-88 